\title{
The Application Analysis of Task-driven Teaching Method in CPA Audit Panpan Du
}

\author{
Xijing University, Shaanxi, Xi'an 710123, China
}

\author{
Keywords: Task-driven teaching method, CPA audit, Application, Analysis
}

\begin{abstract}
CPA audit is a very important but comparative difficult content of the professional courses in the CPA teaching orientation in Accounting major. At present, in the professional teaching process of CPA, what has been instructed is the audit related theories with the teacher as the class subject and students passively as the knowledge receiver. Also, the specific teaching methods are very limited. Teachers pay attention to blindly instilling knowledge and the teaching procedure of examples in the class has been restrained in partial aspects of auditing. This kind of teaching method has prevented the students' learning initiative and motivation to be developed so that their own abilities cannot be improved. Therefore, traditional teaching methods should be reformed and innovated by actively using task-driven teaching method so as to promote the realization of teaching objectives of CPA audit.
\end{abstract}

\section{Introduction}

CPA audit stated in this article is to fully consider the goal of training the talents of financial management specialty and requirement of professional quality of CPA position, and to jointly develop the "Accounting major" together with accounting firms. The major teaching objective is to develop students' auditing ability and self-supervision capability. However, the teaching method in present auditing course is single so that the implementation of auditing practical operation is difficult. Also, most students feel hard to understand the abstract knowledge. Vocational education should be aimed at the comprehensive cultivation on students' professional ethics and skills and students' continuous developing ability. The application of task-driven teaching method to the teaching process of CPA audit can further improve the teaching efficiency and quality.

\section{Introduction of task-driven teaching method}

The detailed content of so-called task-driven teaching method is to actively propose the problem-solving methods and approaches with the completion of specific task as the main clue under correct guidance of the teacher and then to carry out the specific operation. Students can learn new knowledge by means of completing tasks so that they can better discover and solve problems [1]. This kind of teaching method has fully presented the organic combination of the dominant role and the subjective role, which is also the main principle of teaching design. It can effectively avoid the teacher-student contradiction happened during the teaching design that the teacher is dominant and students receive passively. It can fully develop the teacher's leading role, but also can highlight the student's subject status. To some degree students' learning motivation has been initiated and their ability of knowledge application and innovation has been improved. Teacher will take corresponding professional attitude to actively mobilize students so that students can learn more actively and innovatively.

\section{The specific application of task-driven teaching method in CPA audit}

At present in the teaching process of CAP audit, teachers can transfer the knowledge that requires students to master in the way of task-driven into a teaching process of completing tasks to solve problems. In this process, teachers can divide the related courses of CPA audit into three different teaching situation modules, and then based on above modules divide auditing tasks into contents 
which are more convenient for students to learn single item of auditing. During the process, the proposal, analysis, completion, and evaluation of tasks are required so that students can better grasp professional knowledge and skills, even methods and techniques during the process of finishing learning tasks.

\section{The proposal of tasks}

Fully consider students' practical situation and modern vocational education objectives, and based on this, always adhere to the developing rule of students' vocational ability. Analysis on workers required in auditing positions and professional abilities in the society can be regarded as important basis, to divide course contents according to the specific job duties and procedures in auditing positions into three interconnecting learning content situations, basis knowledge, auditing methods and procedures, and cycle auditing practice [2]. In practical working process, each learning content situation should be divided to form multiple working tasks. Reasonably design corresponding operation steps, methods procedures on the condition of working tasks so that finally construct a scientific teaching content system to realize the perfect combination of theoretical learning and practical operation.

First is the basic knowledge module. Three tasks have been set up in this module: the auditing environment, auditing objective, and the code of professional ethics for CPA.

Second is the auditing method and procedure module. This module is divided into four tasks including the plan of auditing, proof and working paper of auditing, risk assessment and response, and the auditing sampling.

The third is cycle auditing module. Considering the designed contents involving its thinking pattern based on the sequence of working tasks, this module mainly includes multiple specific teaching situations and each specific teaching situation is divided into different learning tasks so as to organize the teaching normally. First is the sales and collection situation. In this situation, there are four substantial procedures including the operating income, debt receivable, selling expenses, and tax payable. Second is the purchasing and collection situation [3]. There are three procedure tasks including accounts payable, fixed assets, and administrative costs. The third is production and inventory situation also including three tasks of procedure contents, inventory, operating cost, employees' salary payable. The fourth is the investment and financing situation. There are a lot of task contents in this situation including six procedure contents of trading financial assets, short \& long term loan, income from investment, financial cost, books received and capital reserve. The fifth is monetary capital situation. This situation mainly including procedure contents of cash on hand, deposit in bank and other monetary funds. The sixth is auditing ending situation mainly including procedure contents of the summarizing before issuing the audit report and the officially issued auditing report.

\section{Analysis on tasks}

After the proposal of tasks, teachers need to guide students correctly so that they can make a comprehensive discussion and analysis on tasks and clearly propose things required to be done in the task. Aiming at the relative common sense and fundamentality, teacher should direct students on professional knowledge they have learned before so that they can independently propose the solution. In the process of practical auditing formulation, for new tasks and knowledge involved, teachers should also give relative guidance and provide corresponding tools and methods to solve problems. Meanwhile make them independently raise the way to solve problems so as to formulate specific design to finish the task [4]. In the auditing process for students to identify the actual amount of cash, they think it necessary to check cashes firstly. But the way to check cashes, approach to check records, and how to use checking results to prove the statement announcement are all new knowledge involved in the process of completing tasks. So teachers should guide student and design scientific and reasonable problem-solving design after overall discussions. 


\section{The completion of tasks}

After confirming specific solution, students should start learning focusing on the specific contents of the solution and do their best to try and unlock so as to finish the learning task and to comprehensively understand and flexibly apply professional knowledge. According the basis accountancy and accounting and finance, problems like students' filling in cash checking form , whether actual amount of cashed obtained can reach the auditing target when checking and recording, and conditions and factors still absent in the process of completing auditing tasks should be considered during the process. For realizing auditing objectives, advanced checking forms should be improved relatively during the learning process and it requires to actively proposing the task contents in each procedure. Meanwhile, teachers should actively propose the late-stage tasks and present the actual auditing working process to students in the form of tasks. Then under this background, teachers timely answer questions raised by students. In this way, teachers can fully use the accounting firm's inventory cash auditing paper in real work to guide student for carrying out teaching contents of simulation operation actively.

\section{Evaluation of the result}

Regarding the characteristics and features of CPA audit, teachers must pay attention to knowing and following up students' attitude toward their participation into the practical teaching activities. Meanwhile, for students' problem-solving ability and innovation, teachers should also pay attention according to students' performance during the process their obtaining knowledge and experience and lessons. In this way, students' learning quality and ability can be really improved. In the practical evaluation process, the contents to be evaluated should be focused on the overall evaluation on students' comprehensive application of their professional knowledge and their practical innovation ability. Regarding the specific evaluation method, teachers should fully consider the features of the course and try to achieve the organic combination of process-result evaluation, theory-practice evaluation, with expert-teacher evaluation so as to provide objective and fair evaluation on students' professional ability in this evaluation approach.

Courses of CPA audit will be examined. The evaluation performances will be made by students' performance in knowledge identification and ability identification with the same portion of 50\%. There are grades of students' learning process and learning results. The examination evaluation is to strictly examine and fairly assess how students understand the auditing practice theory and how they master the auditing practice operation skills. The performance of courses is made of grades from the instructing teacher and grades from expert team. During the process of evaluating on learning process and results, students' knowledge and skills should be comprehensively assessed. Students' individual training program and theoretical knowledge requires teachers to test according to their specific learning process and results. In addition, students' position skills will be evaluated by the expert team according to their individual performance and results.

\section{The enlightenment analysis of the application task-driven teaching method in CPA audit}

In the application of task-driven teaching method, an important precondition is to guarantee its strong applicability of professional courses. In the course teaching of CPA audit, active application of task-driven teaching method can mobilize students' learning initiative and consciousness to a certain extent. It also strengthens their sense of achievement and self-confidence when students are discovering and solving problems. In addition, the process of applying task-driven teaching method has enhanced the request for teachers accordingly [5]. Therefore, the instructing teacher needs to carefully prepare for teaching before class to make sure the design of class teaching is more vivid. Meanwhile, teachers' own qualifications on rich social practical experience should be guaranteed. Also teachers should comprehensive know and master the specific working process in accounting firms and contents of CPA audit. On this basis, they need to get familiar with accounting profession and relative course contents so as to make sure that teachers can make scientific and reasonable 
design on students' learning tasks based on auditing cases collected in the real society. Then make sure that students can actively explore and practice during the process of completing design tasks so that their imagination and judgment can be improved accordingly and finally they can better obtain the auditing methods and techniques in the professional teaching contents.

It can be seen that active application of task-driven teaching method in the course teaching process of CPA audit has positive effect. Make reasonable division of course teaching contents in the form of learning tasks to students and make sure that students can accept the specific contents in the tasks. This task-driven teaching method can help students independently explore and learn during the process of completing tasks and also can effectively develop their practical and innovative abilities to independently explore and learn new knowledge. Also, it can effectively develop students' practical and innovative capabilities and enhance their professional qualities and technical skills so that they can get fully development in the process of learning professional knowledge. The application of task-driven method can help students better understand the contents when learning CPA audit course, learn step by step, break through gradually, and strengthen students' personal self-confidence so as to promote their study on professional knowledge better and enhance their learning activity and initiative. Practice has proved that task-driven teaching method has achieved ideal result in the application on CPA audit course. So this method can be applied to other suitable professional teaching so as to actively promote the positive development of other professional teaching.

\section{Conclusion}

To sum up, in the process s of education system reform, the task-driven teaching method is a brand new teaching method produced in the long-term exploration process. No matter for students or teachers, this teaching method has proposed better requirement and also a gradually adaptable process. The implementation approach and method of this teaching method needs to be improved and perfected continuously. Only in this way can we apply task-driven teaching method to the teaching process. The article has focused on the specific application process of task-driven teaching method in CPA audit course. In the long-term practice process, this teaching method has significant application effect in the professional course and has effectively improved students' learning efficiency and quality. Therefore, we can say that this teaching method has certain promotional value. The article has made a comprehensive analysis on task-driven teaching method, and elaborately discussed the specific application in the teaching process of CPA audit course. Students in this major have improved their learning initiative, explore more actively, and positively discover and solve problems during the process of learning professional knowledge through practical application of this teaching method, so that their vocational quality and professional skills have been improved accordingly. Therefore, this teaching method has certain practical significances.

\section{Acknowledgement}

The topic title of this article: The innovative research of application-oriented personnel training mode as the goal of cultivating CPA, Topic No. JGYB1512

\section{Reference}

[1] Wu Zhiyong, Application of task-driven teaching method in CPA Audit, Brand, 2012(1):67,74.

[2] Feng Yinqing, Teaching method research on CPA professional tax low based on task-driven teaching method, Education teaching forum, 2013(41):78-78,79.

[3] Wang Yanfang, Task-driven case teaching: new thought on higher vocational auditing teaching. Commercial Accounting, 2013(8):117-118. 
[4] Xia Sailian, Application of task-driven case teaching in the higher vocational course of "Auditing practice", Commercial Accounting, 2014(21):120-121.

[5] Yan Xiaoyun, task-driven teaching mode and auditing teaching, Chinese \& Foreign Entrepreneurs, 2013(28):248-248. 